\title{
SSR analysis of pea (Pisum sativum L.) cultivars and lines \\ Gainullina K.P.
}

Institute of Biochemistry and Genetics - Subdivision of the Ufa Federal Research Centre of the Russian Academy of Sciences, Ufa, Russia; Bashkir Research Institute of Agriculture - Subdivision of the Ufa Federal Research Centre of the Russian

Academy of Sciences, Ufa, Russia

E-mail: karina28021985@yandex.ru

Key message. The analysis of molecular genetic diversity of pea cultivars by microsatellites was conducted. A high level of polymorphism of SSR loci which allows using them for identification of the studied cultivars and lines was revealed

Keywords: pea, cultivar, microsatellite markers, genetic polymorphism

The study of genetic polymorphism of cultivars and lines of pea (Pisum sativum L.) from the world VIR genetic resources gene bank is an important task of modern science and the basis for the preservation of the gene pool of this valuable highprotein agricultural crop. Microsatellite markers that are characterized by high level of polymorphism, wide genomic distribution, and co-dominant inheritance have been used successfully to study genetic diversity. So, the aim of research was to study of molecular genetic polymorphism of microsatellite loci of pea in conditions of the pre-Ural steppe of the Republic of Bashkortostan. Molecular genetic study of 40 pea cultivar samples of different ecological and geographical origin was

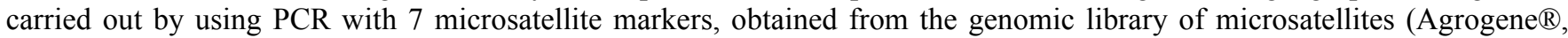
France). Pea seeds were sprouted in Petri dishes. DNA was isolated from 5-7 days-old seedlings using the kit «Genomic DNA Purification Kit» («Thermo Fisher Scientific», Lithuania). Amplification products were separated in 10\% polyacrylamide gel. All microsatellites used in the work gave good electrophoretic profiles. It was amplified a number of alleles per locus varying from 2 (AB53) to 9 (AD355). Total number of alleles was 36 and an average number of alleles per locus was 5.1. The polymorphism information content (PIC) varied from 0.43 for locus AA255 to 0.82 for locus AA355, with an average value of 0.63. The set of SSR-markers used in the work allowed separating each of studied pea genotypes. Genetic distances computed have been used to draw dendrogram showing the distribution of genotypes according to their genetic relationship. The genotypes combined in common clusters shared similar origin, morphological and economically valuable traits. In general, the obtained results suggest that microsatellite markers are an effective tool for identification of genotypes and assessment of genetic diversity in pea.

\section{SSR-анализ сортов и линий гороха посевного (Pisum sativum L.)}

Гайнуллина К.П.

Институт биохимии и генетики - обособленное структурное подразделение Федерального государственного бюджетного научного учреждения Уфимского федерального исследовательского центра Российской академии наук, Уфа, Россия; Башкирский научно-исследовательский институт сельского хозяйства - обособленное структурное подразделение Федерального государственного бюджетного научного учреждения Уфимского федерального исследовательского центра Российской академии наук, Уфа, Россия

Аннотация. Проведен анализ молекулярно-генетического разнообразия сортообразиов гороха по микросателлитам. Bыявлен высокий уровень полиморфизма SSR-локусов, позволяющий использовать их для идентификации изученных сортов и линий.

Ключевые слова: горох, сорт, микросателлитные маркеры, генетический полиморфизм

Изучение генетического полиморфизма сортов и линий гороха посевного (Pisum sativum L.) из мировой коллекция генетических ресурсов ВИР является важной задачей современной науки и лежит в основе сохранения генофонда этой ценной высокобелковой сельскохозяйственной культуры. Для изучения генетического разнообразия с успехом применяются микросателлитные маркеры, отличающиеся высоким уровнем полиморфизма, широким распространением в геномах и кодоминантным типом наследования. Целью работы было изучение молекулярногенетического полиморфизма микросателлитных локусов коллекционного материала гороха посевного в условиях Предуральской степной зоны Республики Башкортостан. Молекулярно-генетический анализ 40 сортообразцов гороха посевного различного эколого-географического происхождения проводили методом ПЦР с использованием 7

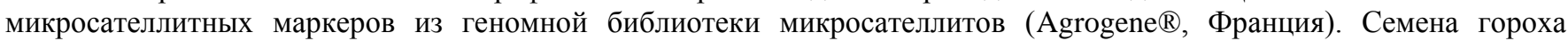
проращивали на чашках Петри. ДНК выделяли из 5-7 дневных проростков с помощью набора «Genomic DNA Purification Kit» («Thermo Fisher Scientific», Литва). Продукты амплификации разделяли в 10\% полиакриламидном геле. Все использованные в работе микросателлиты давали четкие электрофоретические профили. Число амплифицированных аллелей на локус варьировало от 2 (AB53) до 9 (AD355). В общей сложности было выявлено 36 аллелей, в среднем 5,1 аллелей на локус. Индекс полиморфизма варьировал от 0,43 для локуса AA255 до 0,82 для локуса AA355, в среднем составляя 0,63. Совокупность использованных в работе SSR-маркеров позволила однозначно идентифицировать каждый из изученных генотипов гороха. Вычисленные генетические расстояния были использованы для составления дендрограммы, демонстрирующей распределение генотипов в соответствии с их генетической близостью. Генотипы, объединенные в общие кластеры, были схожи по происхождению и некоторым морфологическим и хозяйственно-ценным признакам. В целом полученные результаты свидетельствуют о том, что микросателлитные маркеры являются эффективным инструментом для идентификации генотипов и оценки генетического разнообразия гороха посевного. 